\title{
Seismic Performance and Flexural Stiffness Variation of Assembled Precast High-Strength Concrete Beam Jointed at Mid-Span Using Transverse Bolts
}

\author{
Hassane Ousalem $^{1}$, Yuji Ishikawa ${ }^{2}$, Hideki Kimura ${ }^{3}$, Tetsu Kusaka ${ }^{4}$, Nobuyuki Yanagisawa ${ }^{4}$ and \\ Keijiro Okamoto ${ }^{5}$
}

Received 19 November 2008, accepted 19 April 2009

\begin{abstract}
Assembled precast members and related connections should be economically feasible, bring ease of construction, and provide acceptable static properties as well as adequate dynamic characteristics in high seismic zones. The seismic performance of an assembled precast high-strength concrete beam with a simple and innovative lap splice connection in high-rise buildings is discussed. The flexibility variation along the lap splice connection of the beam, which involves a reduced profile, is also investigated. The lap splice connection, located at beam mid-span, was connected by transverse untensioned bolts. The simplicity of the form and developed mechanism are intended to be suitable for construction sites. The experimental test results confirmed the adequacy of such assemblies to satisfy a safe level under different loadings. The beam under reversed cyclic loading proved to be ductile and failure occurred outside the lap splice connection similarly to monolithic ordinary reinforced concrete beams. The flexural stiffness varied along the lap splice connection of the assembled beam and declined at the transition section of the reduced profile under large loading. Therefore, this reduction, within design limits, would not affect the performance of the assembled beam.
\end{abstract}

\section{Introduction}

\subsection{Assembled precast concept}

Precast, known also as prefabricated, construction concerns those structures where the majority or the totality of structural components are standardized and produced in plants or in situ and then brought to assembly. Therefore, various methods and shapes have been practiced for simple and large constructions depending on the era (Hieber et al. 2005). Despite its potential benefits in terms of construction speed and quality control, precast construction, particularly framed construction, was not used extensively in high-seismic regions due to the lack of appropriate understanding of various parameters, as well as the lack of prescriptive guidelines for the comprehensive use of precast systems, particularly when the connections of precast components are located in sensitive places of structural systems or are of unusual forms. Although some guidelines have suggested detailing requirements based on practices related to monolithic sys-

\footnotetext{
${ }^{1}$ Researcher, Research and Development Institute, Takenaka Corporation, Japan.

E-mail:ousalem.hassane@takenaka.co.jp

${ }^{2}$ Chief researcher, Research and Development Institute, Takenaka Corporation, Japan.

${ }^{3}$ Senior manager, Tokyo Head Office, Takenaka Corporation, Japan.

${ }^{4}$ Manager, Osaka Main Office, Takenaka Corporation, Japan.

${ }^{5}$ Engineer, Tokyo Head Office, Takenaka Corporation, Japan.
}

tems (PCI 1997; BD 2003; Miller et al. 2004), such approaches cannot be easily accomplished in full precast systems (Khaloo and Parastesh 2003). To overcome such shortcomings and raise confidence in the use of precast frames, various studies and laboratory testing have been conducted recently to validate their performance. While the main focus of these studies has been the structural performance of assembled precast elements under different loadings, some solutions did not seem to be cost competitive due to the form and the weight of the precast elements, as well as the amount of cast-inplace concrete for assembling and its curing time, which significantly affect the construction cycle, and consequently the construction cost.

To achieve an appropriate practice regarding this issue, an extensive experimental program, which includes the study presented herein, which focuses only on the beam mid-span connection, has been carried out, investigating the performance of different assembled uncomplicated high-strength concrete precast elements (Ousalem et al. 2008b). In this program, the beam-column joint core was cast with protruding beam cantilevers (lap elements), while the column formed another precast member (Fig. 1). To assemble the precast parts, the beam-column joint core was provided with vertical ducts to pass through the main bars of the lower column. These bars were lodged in splice grout-sleeves located at the bottom of the upper column to ensure an adequate splicing after injection of high-strength mortar. The connection of the precast cantilever parts was conceived at beam mid-span, where different mechanical systems were investigated (Ousalem et al. 2008a), simultaneously with the system put forth in the present study. The 


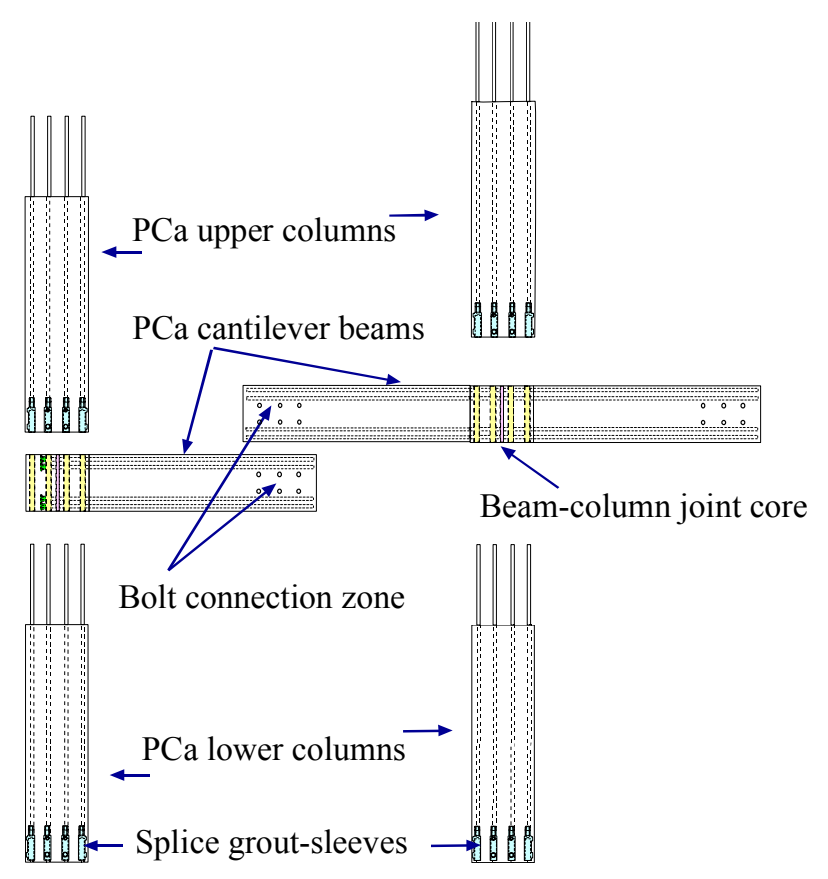

Fig. 1 Proposed precast member assemblages (elevation).

aim of the test program was to present design guidance for easy high-strength concrete precast member connections in high-rise buildings located in high seismic regions.

\subsection{Literature survey}

While various studies have been carried out on precast frames, the investigated solutions and connections were almost all conceived around the beam-column joint with, generally, a certain amount of cast-in-place concrete for assembling.

Abd-Rahman et al. (2006) investigated the moment of resistance and the behavior of pinned beam-tocolumn connection in precast concrete frames. Beams were jointed with supported corbels in precast columns. Steel connectors, such as angles, plates and bolts, as well as single dowel bars projecting from the corbel, were used. Tested specimens exhibited ductile behavior, however, to maintain the stability of a whole frame, and to provide global stiffness, other lateral stability systems such as bracings or walls should be added.

Stone et al. (1995) investigated hybrid connections without shear-keys and corbels that contained mild steel and post-tensioning steel, both of which contributed to the moment resistance. Combinations including bonded and unbonded bars for mild and post-tensioned bars were considered and prestressed strands locations were varied on the beam height. The proposed systems showed considerable promise but not all of the details worked perfectly.

Part of the experimental work carried out by Amaris et al. (2006) closely paralleled Stone's study. Specimens comprised unbonded draped varying longitudinal profile tendons anchored at exterior columns, steel shear bracket/corbel and mechanical hinges with external dissipaters, acting as shear key solutions. Tested specimens showed very satisfactory performance and the hybrid system comprising mechanical hinges and dissipaters proved to be of high flexibility. The study concluded that the appropriate technological solution would be chosen within the available systems on a case-by-case basis.

Khaloo and Parastesh (2003) tried to evaluate the performance of a relatively simple precast beam-column concrete connection for moment-resisting without the use of prestressing technology. The end portion of the beams was designed in the form of a channel that sat on the column-bearing area and carried shear stresses due to the slab. The connection length was conceived inside the beam-ends where the reinforcement extending from the column was lap-spliced with beam reinforcement and/or end-anchored, then the channel-shaped space was grouted. The proposed connections were capable of providing strength, ductility and energy dissipation comparable with that of monolithic connections for lowrise frame structures of regions with seismic activity.

Khoo et al. (2006) proposed an assembled configuration for precast concrete frames in which the connections were conceived on the beam span and kept away from the columns' faces. The connections were established through the lapping of hooks with two different configurations (common and modified ones) at the precast beam ends, which were encased within cast-inplace concrete. The selected configurations implied that a beam-column joint core with short protruding beam stubs was cast as part of the precast column, while the beam spanning in between columns would form another precast member. It was reported that the modified configuration was feasible as a replication of cast-in-place moment-resisting frames and was appropriate for providing sufficient seismic resistance in areas of low-tomoderate seismicity.

Contrary to the proposal of Khoo et al. (2006), another concept that shifts the beam connection to the mid-span and replaces the relatively considerable amount of cast-in-place concrete by a small amount of cement mortar was proposed by the authors and investigated for high-seismic regions. Experimental work was carried out to study the performance of an easy highstrength precast beam connection conceived at the assembled beam mid-span. The assembled beam was composed of two symmetric similarly detailed, precast lap elements (Fig. 2). While the lap element depth was kept unchanged, the cross section in the connection zone was abruptly reduced to half to allow splicing of the lap elements. Transverse bolts were used to join the lap elements and high-strength cement mortar was grouted into gaps to form a rigid connection. The concept was to mechanically approach the monolithic case, be cost competitive and bring ease of construction. The connection study was composed of two phases. A study concerning the seismic performance of the whole assembled precast beam as well as the lap splice connec- 
tion was first carried out, followed by another study regarding the variation of the flexural stiffness along the lap splice connection.

\section{Description of experimental program}

\subsection{Details and construction of test specimens}

The test program included two assembled high-strength concrete precast beams of similar cores, cross-sections, detailing, connections and materials. Figure 2 and Fig. 3 illustrate the geometric characteristics and detailing of each beam as well as the connection details.

The basic specimen, denoted Beam B-C (Fig. 2) and representing interior shallow beams on closely spaced columns in high-rise buildings, was a half-scale beam with a clear length of $2.2 \mathrm{~m}$. The length of the other specimen, denoted Beam B-M (Fig. 3), was designed with an extended length in order to carry out a flexural stiffness study along the lap splice connection under pure bending. This loading permits the examination of the connection without major interference from shear deformation. Furthermore, while the scaling applied to all beam dimensions, the size of the reinforcement was selected according to the required amount. Both beams were intended to be dominated by flexural behavior and scaling would not affect the interpretation of their performances. The design of the beam was based on longand short-term loads where the flexural strength was evaluated to be controlled by the detailing of the beam end section (Section A-A in Fig. 2). On the beam end section side, the longitudinal reinforcement of the beam was conceived to be extended through the body of the beam-column joint (Fig. 1) in the case of an interior beam-column joint or to be mechanically anchored into the beam-column joint in the case of an exterior beam column joint. On the lap element part, the required amount of longitudinal reinforcement was extended from section A-A to fulfill the flexural strength relative to the combined effect of long- and short-term loads based on the moment ratios between the beam endsection and the transition section (cross-section where the area abruptly changes from full to half area).

Each beam was precast into two cantilevers with 500 $\mathrm{mm}$ long lap elements. The connection was conceived with two rows of 4 transverse bolts. The bolts were not tensioned and were just finger-tight, maintaining a constant $10 \mathrm{~mm}$ gap between the precast cantilever parts for grouting. The $10 \mathrm{~mm}$ gap (dry grout-joint) and the voids

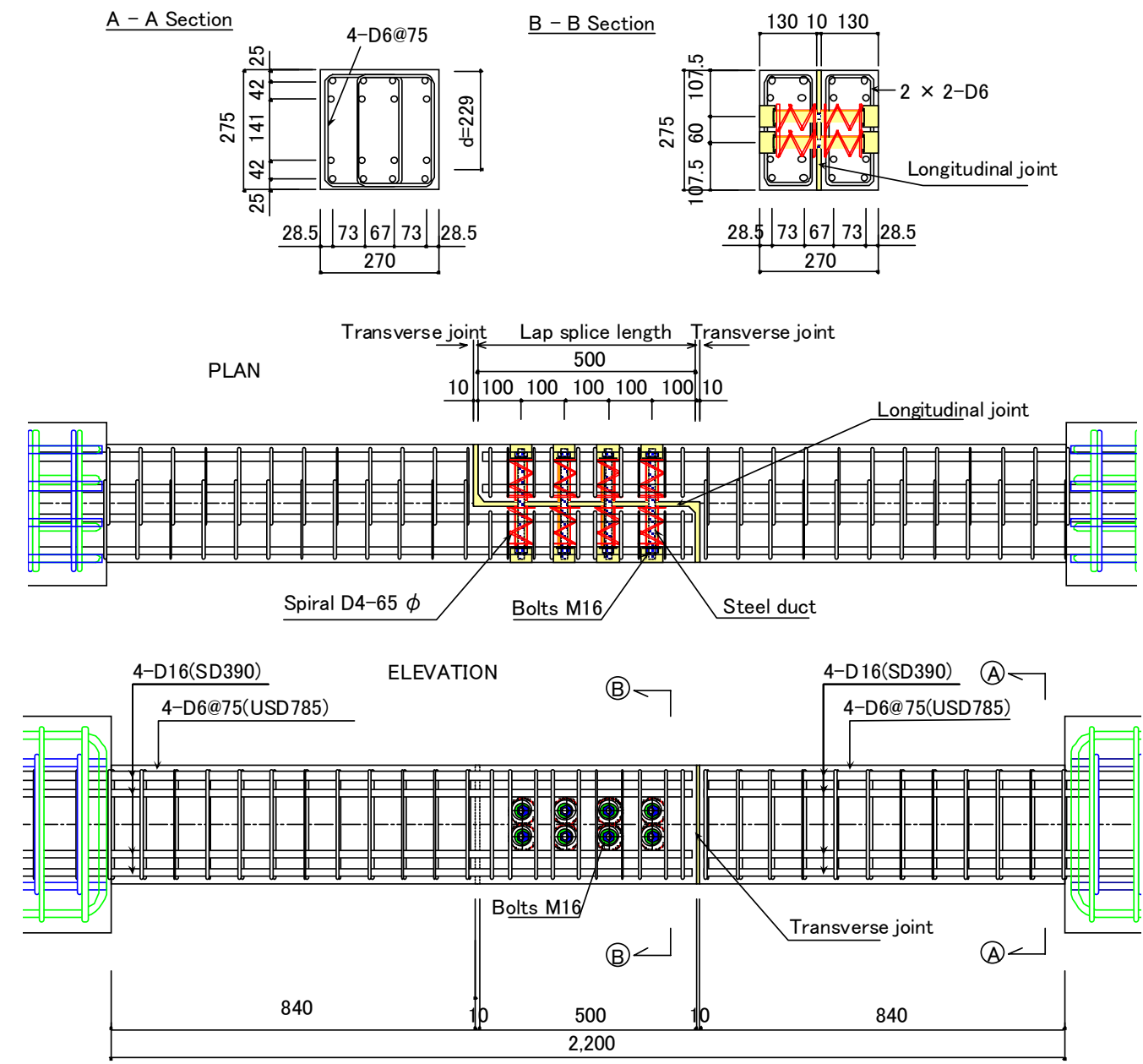

Fig. 2 Assembled precast beam for cyclic reversed loading (beam B-C). 


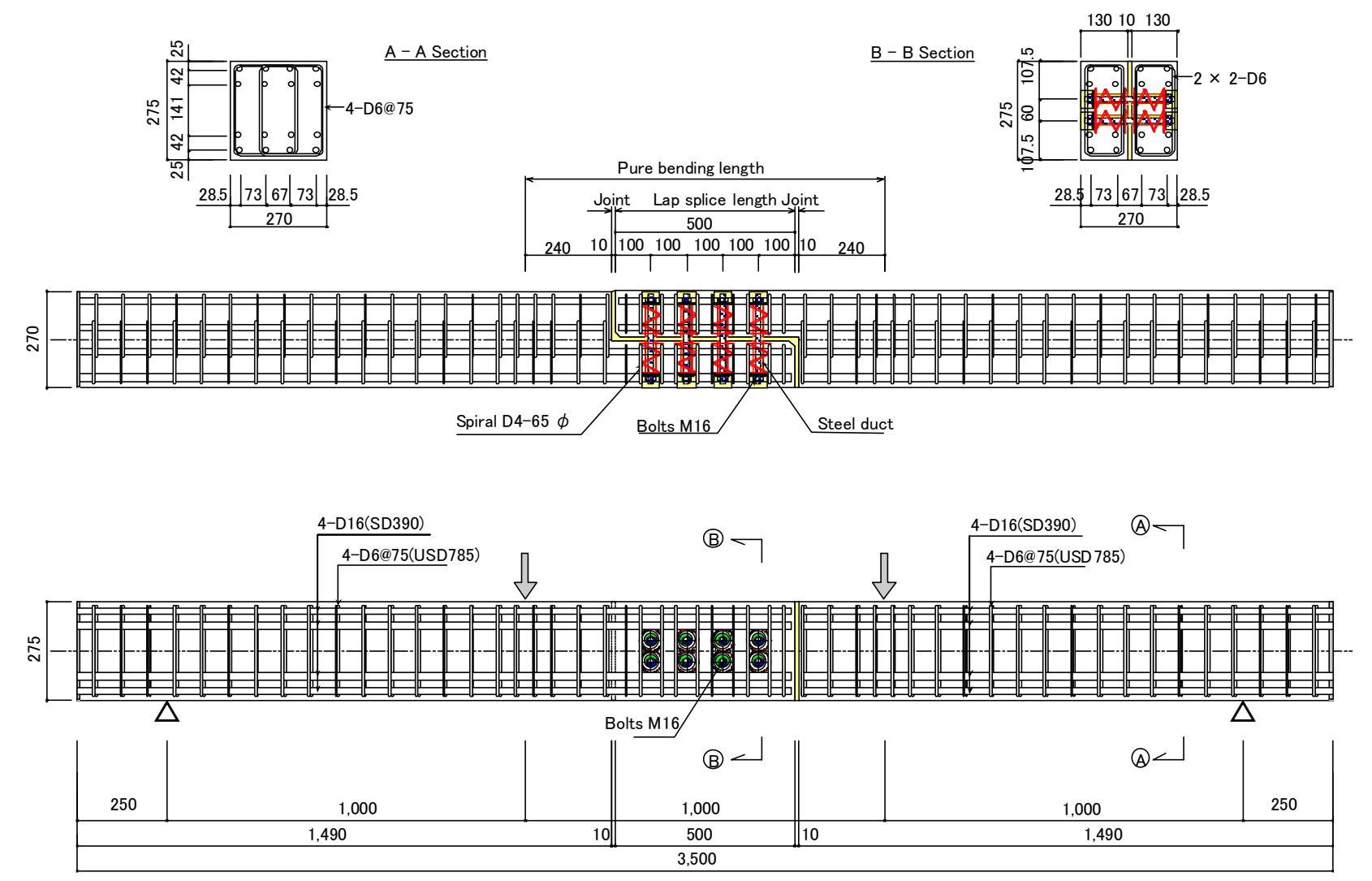

Fig. 3 Assembled precast beam for four-point loading (beam B-M).

surrounding bolts were grouted with very high-strength cement mortar. The load is intended to transfer from one precast part to another precast part through the reaction of the transverse bolts (refer to Fig. 8).

High-strength concrete (nominal strength $f_{c}=60$ $\mathrm{MPa}$ ) was used in the casting of the test specimens. The maximum aggregate size was $20 \mathrm{~mm}$. Also, highstrength cement mortar (nominal strength $\mathrm{f}_{\mathrm{c}}=80 \mathrm{MPa}$ ) was used to fill gaps and voids in the assembled beams.

The longitudinal and transverse reinforcements used for the test specimens were, respectively, normal and high-strength bars of Grade SD390 (nominal strength $f_{y}$ $=390 \mathrm{MPa})$ and Grade USD785 $\left(\mathrm{f}_{\mathrm{y}}=785 \mathrm{MPa}\right)$. D16 (deformed bar with $16 \mathrm{~mm}$ nominal diameter) bars were used for longitudinal reinforcement while D6 stirrups formed the transverse reinforcement. As to connection bolts, $250 \mathrm{~mm}$ long M16 bolts of F8T type $\left(f_{y}=800\right.$ $\mathrm{MPa}$ ) were used along with M-16 nuts of HTB-type. Two $3.2 \mathrm{~mm}$-thick washers of $40 \mathrm{~mm}$ diameter were used for each bolt. The concrete part surrounding the duct for bolts was reinforced by a D4-65Ø steel spiral. The properties of all materials as obtained by laboratory tests are listed in Table $\mathbf{1 .}$

\subsection{Instrumentation and loading arrangement}

The tested beams were instrumented internally and externally. Strain gauges were installed on the reinforcement at different locations, particularly at hinge and connection zones. Displacement transducers were in-
Table 1 Properties of tested materials (MPa).

\begin{tabular}{|l|c|c|c|}
\hline & $\mathrm{f}_{\mathrm{c}}$ & $\mathrm{E}_{\mathrm{c}}$ & $\mathrm{f}_{\mathrm{t}}$ \\
\hline Concrete & 74.9 & 37500 & 3.5 \\
\hline Cement mortar & 89.1 & 30700 & - \\
\hline \multicolumn{4}{|l}{} \\
\hline Reinforcement & $\mathrm{f}_{\mathrm{y}}$ & $\mathrm{E}_{\mathrm{s}}$ & $\mathrm{f}_{\mathrm{u}}$ \\
\hline D6 (USD785) & 989.4 & 191000 & 1165.5 \\
\hline D16 (SD390) & 461.7 & 197000 & 643.0 \\
\hline M16 (F8T) & 825.3 & 206000 & 1097.5 \\
\hline
\end{tabular}

stalled on beam faces to measure deformations along the beam length as well as at critical sections and at connection interfaces.

As to loading, the beams were tested in a horizontal position. No load was applied axially on both beams. Beam B-C was subjected to a simulated seismic load without superposing the presumable gravity load, assuming the effect of the moment induced by the gravity load on the lap splice connection to be minor compared to the moment developed by a severe seismic load. Thus, the beam experienced an anti-symmetric double curvature bending and was subjected to twice-repeated reverse-cycles with increasing amplitude, including some intermediary cycles of short amplitudes. The loading was displacement-controlled where the deflection angle amplitudes R were (by ratio of 1/1000): $\pm 1.0, \pm 2.0, \pm 3.3$, $\pm 5.0, \pm 2.0, \pm 7.5, \pm 10.0, \pm 5.0, \pm 15.0, \pm 20.0, \pm 5.0, \pm 30.0$, \pm 40.0 and \pm 50.0 . 
Beam B-M was subjected to a-four-point bending load. It experienced a monotonic vertical loading until the ultimate stage with two steps of non reversed cycles. The loading was force-controlled, with the unloading levels corresponding to $1 / 3$ and $2 / 3$ of the beam flexural yield strength, as evaluated based on the measured strength of reinforcement.

\section{Description and discussion of test results}

\subsection{Response description of Beam B-C}

During loading, the tested beam experienced during loading different stages that are illustrated along with the design limits in Fig. 4, which shows the force response related to the controlled deflection angle. The beam showed very good performance where the behavior was completely of flexural type with significant ductility without any clear sign of shear degradation at the end of loading. The displacement ductility level when the lateral loading was concluded was more than twice the ductility level at the design deflection angle $(\mathrm{R}=$ $2 / 100)$ relative to the case of a severe seismic load. The measured flexure deformation (using LVDTs for curvature measurement), when compared to the shear deformation (evaluated by deducting the flexural deformation from the total deformation), was found predominant (Fig. 5). The developed beam mechanism was similar to the mechanism of a monolithic beam. The main test characteristics at different loading levels of the tested beam and the estimated values of a monolithic beam were very close. These values are presented in Table 2 . The moment $\mathrm{M}_{\mathrm{c}}$ and shear force $\mathrm{Q}_{\mathrm{c}}$ at cracking of beamends (section A-A in Fig. 2) and flexural stiffness were evaluated on the basis of the flexural theory for the beam length $L$, the measured concrete tensile strength $f_{t}$ and the section modulus $Z_{\mathrm{e}}$ without consideration of the reinforcement.

$$
\begin{aligned}
& Q_{c}=2 M_{c} / L \\
& M_{c}=f_{t} Z_{e}
\end{aligned}
$$

The flexural stiffness was simply evaluated at cracking level by

$$
M_{c} / R_{c}=\frac{6 E_{c} I}{L}
$$

where $\mathrm{E}_{\mathrm{c}}$ is Young's modulus of concrete and I the gross moment of inertia of the beam section. By substituting Equation (1.b) into Equation (2), the relative deflection $\mathrm{R}_{\mathrm{c}}$ at cracking of the beam was then calculated.

The moment $\mathrm{M}_{\mathrm{y}}$ and shear force $\mathrm{Q}_{\mathrm{y}}$ at yield of beamends (section A-A in Fig. 2) as well as the flexural secant stiffness were evaluated using the proposed formula in AIJ (1990), where $a_{t}$ and $f_{y}$ are, respectively, the tension bars' total section and measured yield strength, and $\mathrm{d}$ the section effective depth.

$$
\begin{aligned}
& Q_{y}=2 M_{y} / L \\
& M_{y}=0.9 a_{t} f_{y} d
\end{aligned}
$$

The flexural secant stiffness at yield point was evaluated using the simple empirical formula developed for reinforced concrete beams and columns subjected to anti-symmetric bending (AIJ, 1990). The axial load component was not included in the formula.

$$
\begin{aligned}
& M_{y} / R_{y}= \\
& \left(0.043+1.63 n p_{t}+0.043 \frac{M}{Q D}\right)\left(\frac{d}{D}\right)^{2} \frac{6 E_{c} I}{L}
\end{aligned}
$$

where $n=E_{s} / E_{c}$ and $p_{t}$ is the tensile reinforcement ratio, $\mathrm{D}$ is the section depth and M/(QD) is the shear span ratio, with $\mathrm{M} / \mathrm{Q}$ taken herein as half of the beam length. By substituting Equation (3.b) into Equation (4), the relative deflection $\mathrm{R}_{\mathrm{y}}$ at yielding of the beam was then calculated.

The beam behavior was characterized by flexural cracking and truss action. Cracks developed symmetrically on both faces (top and bottom) of the beam. At the beginning of loading, flexural cracks at beam ends appeared, followed soon by a crack at the transverse joint

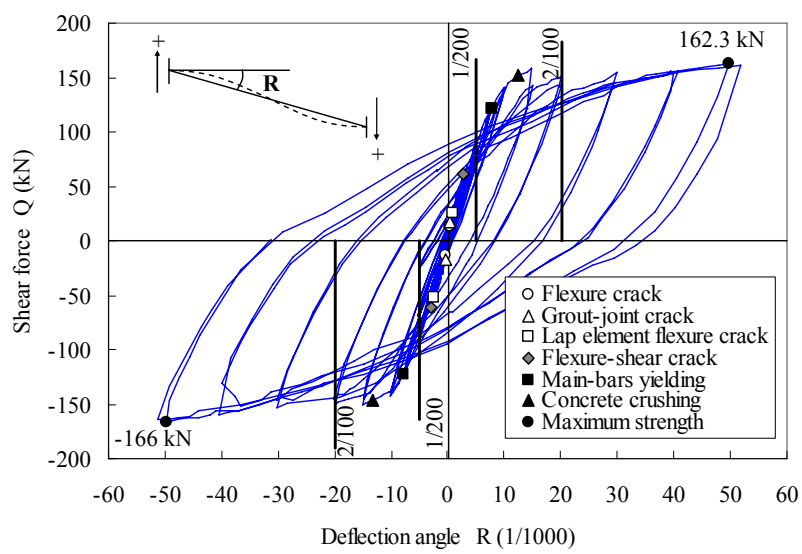

Fig. 4 Shear force-lateral deflection angle response and major events of Beam B-C.

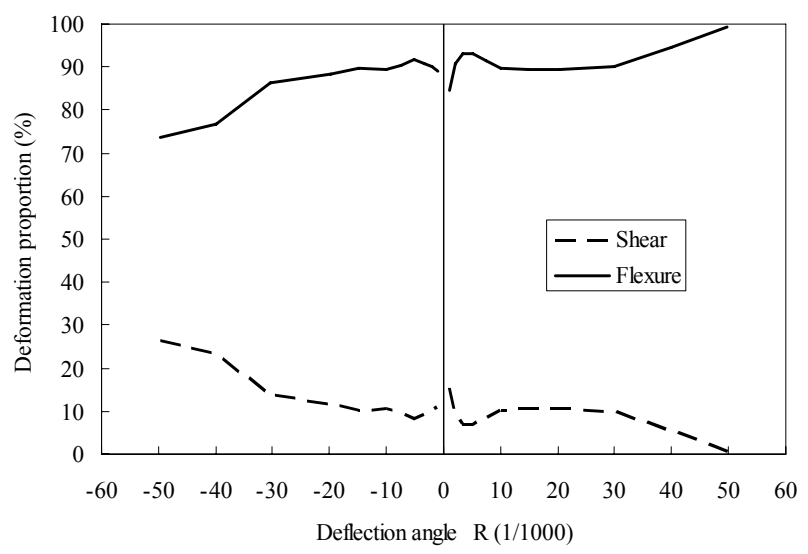

Fig. 5 Flexure and shear deformation proportions of beam B-C. 
Table 2 Main characteristics of tested beam B-C at different stages.

\begin{tabular}{|c|c|c|c|}
\hline & & $\begin{array}{l}\text { Crack } \\
\text { stage }\end{array}$ & $\begin{array}{l}\text { Yield } \\
\text { stage }\end{array}$ \\
\hline \multirow{3}{*}{$\begin{array}{l}\text { Moment } \\
\text { (kN.m) }\end{array}$} & Test & 8.7 & 134.4 \\
\hline & Estimation & $\begin{array}{l}11.9 \\
\text { (Eq. 1.b) }\end{array}$ & $\begin{array}{l}128.0 \\
\text { (Eq. 3.b) }\end{array}$ \\
\hline & Ratio $^{\$}$ & 1.36 & 0.95 \\
\hline \multirow{3}{*}{$\begin{array}{l}\text { Shear force } \\
(\mathrm{kN})\end{array}$} & Test & 7.9 & 122.2 \\
\hline & Estimation & $\begin{array}{r}10.8 \\
\text { (Eq. } 1 . \mathrm{a})\end{array}$ & $\begin{array}{r}116.3 \\
\text { (Eq. 3.a) }\end{array}$ \\
\hline & Ratio $^{\$}$ & 1.36 & 0.95 \\
\hline \multirow{3}{*}{$\begin{array}{l}\text { Flexural } \\
\text { secant } \\
\text { stiffness } \\
\text { (kN.m) }\end{array}$} & Test & 43394.5 & 16938.0 \\
\hline & Estimation & $\begin{array}{l}45559.3 \\
\text { (Eq. 2) }\end{array}$ & $\begin{array}{l}14107.2 \\
\text { (Eq. 4) }\end{array}$ \\
\hline & Ratio $^{\$}$ & 1.05 & 0.83 \\
\hline \multirow{3}{*}{$\begin{array}{l}\text { Deflection } \\
\text { angle } \\
(1 / 1000)\end{array}$} & Test & 0.35 & 7.90 \\
\hline & Estimation & $0.26^{*}$ & $9.07^{* *}$ \\
\hline & Ratio $^{\$}$ & 0.74 & 1.15 \\
\hline
\end{tabular}

before reaching deflection angle level $\pm 0.5 / 1000$. Flexural cracks developed then from beam ends and reached the lap splice connection at the location of the transition section at deflection angle level $+0.8 / 1000$, while on the negative loading-side, flexure cracks reached the lap splice connection at deflection angle level $-2.0 / 1000$. Flexure-shear cracks started at the hinge zone before the peaks of loading cycle corresponding to deflection angle level 3.0/1000. Cracks in the lap splice connection (bolts region) appeared first after the loading cycle corresponding to deflection angle level 5.0/1000 indicating a certain combined interaction at the bolt/high-strength mortar/concrete interfaces. This was followed by a slight partial opening of the longitudinal joint along the beam axis that was induced by torsion-cracks developed at the lap elements soon before the loading cycle corresponding to deflection angle level 7.5/1000. At that deflection level, yielding of main bars started at beam ends. Crushing of concrete at beam-end sections was noticed just before the peaks of the loading cycle corresponding to the deflection angle level $\pm 15 / 1000$ were reached.

Shear force increased with increasing deflection angles (Fig. 4) and when yielding of longitudinal reinforcement was reached at beam ends, the increase in shear strength became limited although the deflection angle increased consistently. No strength degradation was noticed and the ultimate level could not be reached when the test was concluded. Although many flexure cracks and flexure-shear cracks developed at the hinge zone where the damage located, beyond deflection angle $30 / 1000$ relatively slight damage also concentrated around the transition section. The ability of the assembled precast beam to dissipate energy was expressed through the equivalent damping ratio, which was as- sumed to represent the combined effect of all damping mechanisms present in the actual beam during the test. The equivalent viscous damping ratio is given by

$$
h_{e q}=\frac{E_{i}}{4 \pi E_{0}}
$$

where $E_{i}$ is the energy dissipated within each loading cycle $\mathrm{i}$ and $\mathrm{E}_{0}$ is the elastic strain energy stored in an equivalent linear elastic system when the maximum displacement is reached at cycle $i$.

Therefore, the damping ratio resided around $4 \%$ below the deflection angle level of 10/1000 and then increased with cyclic loading amplitudes as shown in Fig. 6 for the variation of the damping ratio during loading at all peak-cycles. Developed cracks and deformed sections did not affect significantly the stiffness of the beam until cycle 10/1000, from where the beam showed an increasing dissipation until the end of the test and insignificant pinching on the loops appeared slightly beyond deflection angle 30/1000.

Strains in transverse reinforcement at the hinge zone and at the lap splice connection were far below the yield level $\left(\varepsilon_{\mathrm{y}}=5200 \mu\right)$, accounting, respectively, for $1 / 2$ and $1 / 5$ of the yield strain. No splitting of concrete near the joint was observed, regardless of how large the axial deformation at the joint interface was. Furthermore, although slight torsion along the lap elements was observed through the course of cracks and data records due to the grout deformation at the interface, at the end of testing, damage could be found neither in bolts nor in their surrounding grout. When the test was concluded and the beam unloaded, it experienced a residual deflection angle of $31 / 1000$. The damage undergone by the beam at the end of loading appears in Fig. 7, where the vertical orange line indicates the location of the transverse joint, while the drawn blue and red lines represent the crack scheme relative to the positive and negative loading directions, respectively.

The observed damage in the lap splice connection was expected when the strength of the connection was assessed using the proposed formula in AIJ (1985). The strength of the connection was assumed to develop pro-

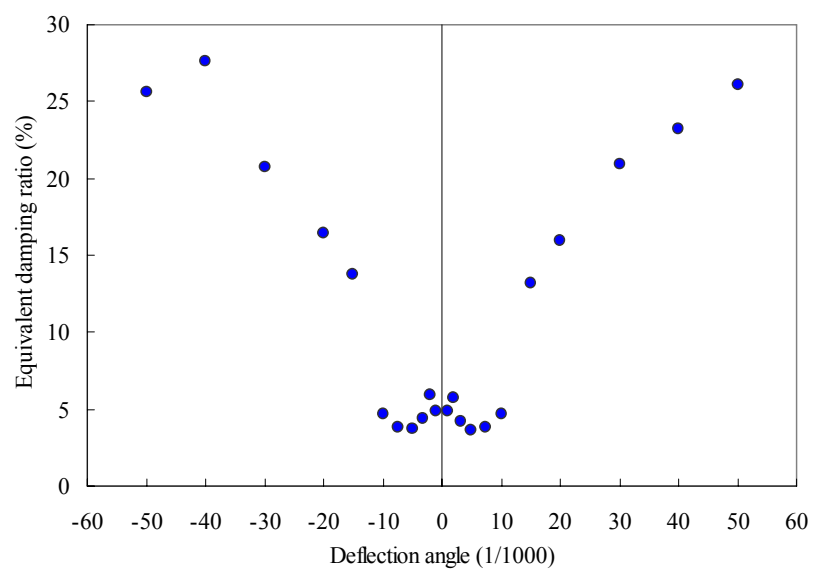

Fig. 6 Variation of equivalent damping ratio of beam B-C. 


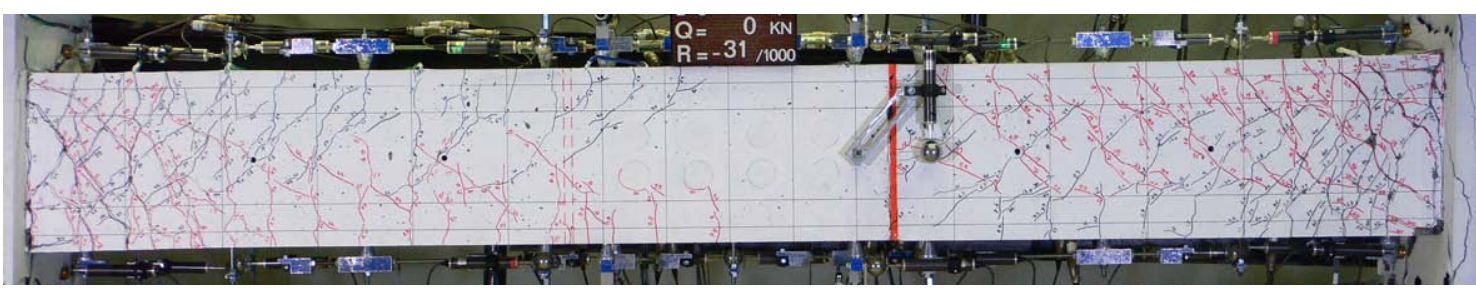

Fig. 7 Final appearance and damage of beam B-C (the transverse joint location is indicated by the vertical orange line).

portionally through non-cumulative components (Fig. 8), assuming no friction along the whole surface of the interface of the lap elements.

First, a connection shear force $\mathrm{Q}_{\mathrm{c}}$ (Fig. 8) was assumed to develop through bearing of the high-strength mortar surrounding the bolts (AIJ 1985).

$$
Q_{c}=\phi_{S 1} 0.5 a_{b} \sqrt{f_{c} E_{c}}
$$

where $\phi_{\mathrm{s} 1}$ was taken to be equal to 0.6 for short-term loading, $f_{c}$ and $E_{c}$ were, respectively, mortar's compression strength and Young's modulus, and $\mathrm{a}_{\mathrm{b}}$ the bolts' cross-section area.

Another connection shear force component, $Q_{b}$ or $Q_{d}$ (Fig. 8), was assumed to develop respectively, by shearresistance or dowel action of bolts (AIJ 1985)

$$
\begin{aligned}
& Q_{b}=a_{b} f_{y b} / \sqrt{3} \\
& Q_{d}=1.65 a_{b} \sqrt{f_{c} f_{y b}\left(1-\alpha^{2}\right)}
\end{aligned}
$$

where $a_{b}$ and $f_{y b}$ are, respectively, the bolts' crosssection area and yield strength, $f_{c}$ the mortar's strength and $\alpha$ a factor accounting for the presence of bending (herein taken to equal 0.5).

The assessed values were far higher than shear force $\mathrm{Q}_{\mathrm{s}}$ at the flexural yield of the lap element considered apart as a separate cantilever element (beam half section and $500 \mathrm{~mm}$ length). To illustrate the comparison, the assessed results are presented in Table 3 .

The growth of cracks was recorded at different locations and at different stages. The crack width was significant at the hinge zone and kept increasing with loading, reaching $1.6 \mathrm{~mm}$ for flexure cracks and $0.3 \mathrm{~mm}$ for flexure-shear cracks at the end of loading. The growth of cracks was also significant at the transverse joint, particularly when the loading cycle corresponded to deflection angle level 5.0/1000 and increased almost ten times, reaching $2.1 \mathrm{~mm}$ at the end of loading.

The lap elements experienced a three-dimensional displacement relative to each other due to the deformation of the joint and opening of cracks at the joint interface along the lap splice connection. The relative displacement at the interface, parallel to the beam axis (referred to as $A_{t}$ and $A_{b}$ in Fig. 9 and measured using displacement transducers), was almost anti-symmetrically similar for both loading sides (positive and negative) beyond the loading level corresponding to deflection

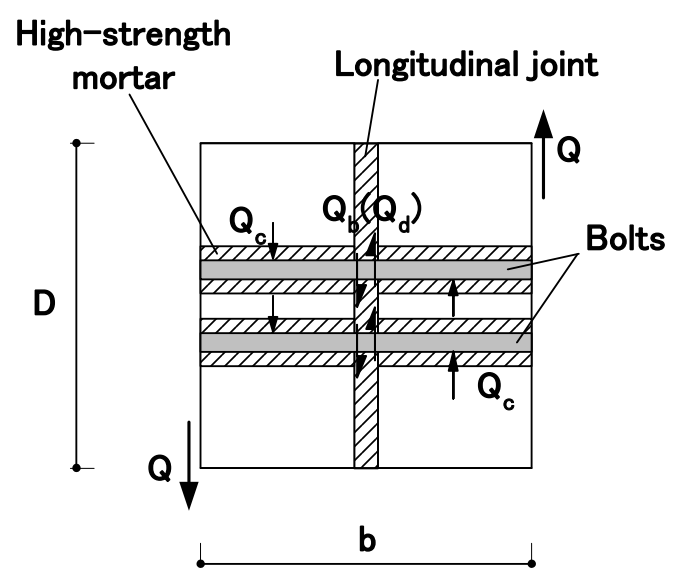

Fig. 8 Free body diagram of presumed developed forces within connection (section B-B of Fig. 2).

Table 3 Estimated shear forces of tested beam B-C at connection zone $(\mathrm{kN})$.

\begin{tabular}{|c|c|c|c|}
\hline $\begin{array}{c}\text { Lap } \\
\text { cantilever } \\
\mathrm{Q}_{\mathrm{s}}\end{array}$ & $\begin{array}{c}\text { Concrete } \\
\text { crushing } \\
\mathrm{Q}_{\mathrm{c}}\end{array}$ & $\begin{array}{c}\text { Bolt shear } \\
\mathrm{Q}_{\mathrm{b}}\end{array}$ & $\begin{array}{c}\text { Bolt } \\
\text { dowel } \\
\mathrm{Q}_{\mathrm{d}}\end{array}$ \\
\hline 296.0 & 601.4 & 584.9 & 410.3 \\
\hline
\end{tabular}

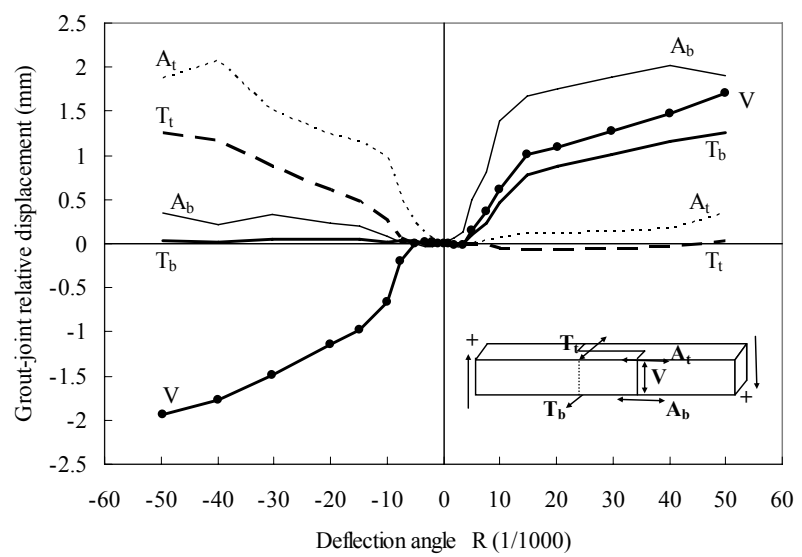

Fig. 9 Relative displacements at grout-joint interface of beam B-C.

angle $10 / 1000$, where the crack width kept increasing with increasing amplitudes while the compression was limited. After the loading level corresponding to deflec- 
tion angle $7.5 / 1000$, the interface on both transverse joint sides experienced a full tension where the relative displacement was of the same sign at both edges of the section height, as shown in Fig. 9. The vertical relative displacement at the interface, parallel to the beam section height (referred to as V in Fig. 9 and measured using displacement transducers), was negligible until the loading level corresponding to deflection angle 5/1000, and then increased with increasing displacement amplitudes.

The transverse relative displacement at the longitudinal joint interface, parallel to the beam section width (referred to as $T_{t}$ and $T_{b}$ in Fig. 9 and measured using displacement transducers), was negligible until the loading level corresponding to deflection angle 3.3/1000, and then increased with increasing displacement amplitudes. This displacement, which would not occur if the lap splice behaved as one rigid body, induced torsion along the lap elements as depicted in Fig. 10. Torsion was confirmed by the recorded axial strains of the bolts. These strains were very low (the maximum axial strain reached $1 / 6$ of the yield level).

\subsection{Response description of Beam B-M}

The tested beam showed a good performance where its behavior was of flexural type until yield occurred at the transition section of the lap elements. The response of the assembled beam to the symmetric forced vertical loading applied at $1 / 3$ of the beam length from the simple supports, represented in terms of the vertical deflections at the beam mid-span, is shown in Fig. 11. In the same figure, a number of major events are also illustrated along with unloading levels corresponding to $1 / 3$ and $2 / 3$ of the flexural yield strength $Q_{y}$ of the beam that corresponded to the flexural yield strength relative to the half beam section.

Shear strengths $\mathrm{Q}_{\mathrm{c}}$ and $\mathrm{Q}_{\mathrm{y}}$ at cracking and yielding, respectively, were evaluated for the symmetric bending distant by the length $a=L / 3$ from the supports.

$$
\begin{aligned}
& Q_{c}=M_{c} / a \\
& Q_{y}=M_{y} / a
\end{aligned}
$$

where the moment $\mathrm{M}_{\mathrm{c}}$ and $\mathrm{M}_{\mathrm{y}}$ were evaluated according to Equations (1.b) and (3.b) for the cases of beam full

\section{Left section Middle section Right section}

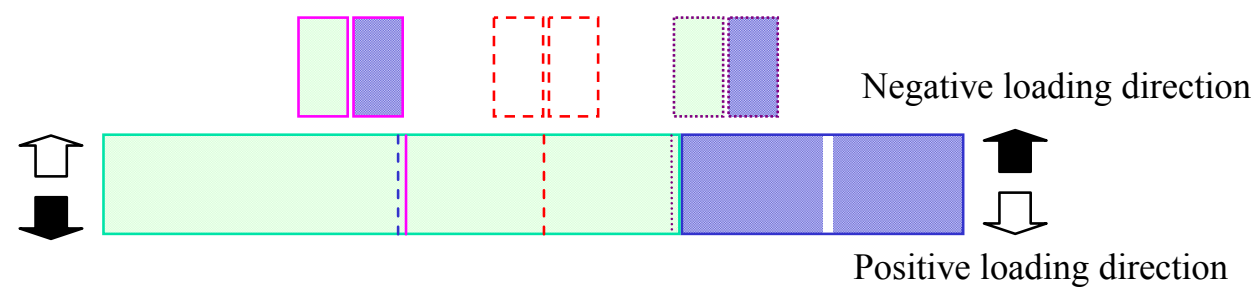

(a)
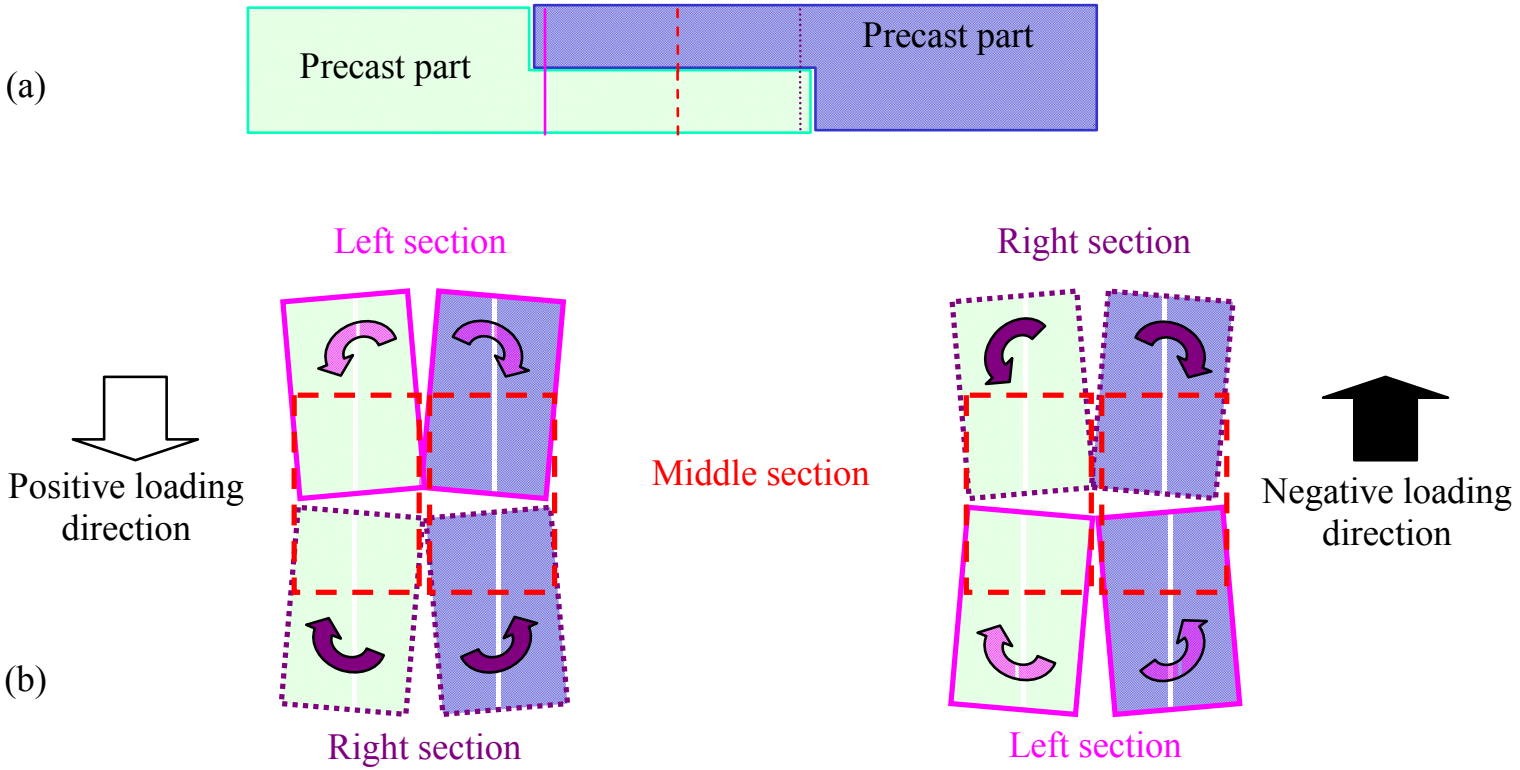

Fig. 10 Developed torsion along lap elements

(a) Sections location (b) Sections exaggerated deformed shapes 


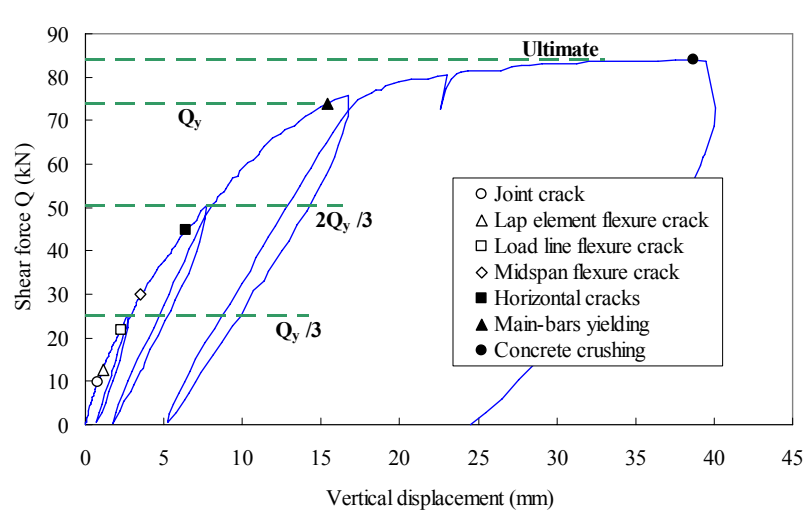

Fig. 11 Shear force-vertical deflection response and major events of beam B-M.

Table 4 Estimated performance of tested beam B-M at different stages.

\begin{tabular}{|l|l|c|c|}
\cline { 3 - 4 } \multicolumn{2}{c|}{} & $\begin{array}{c}\text { Crack } \\
\text { stage }\end{array}$ & $\begin{array}{c}\text { Yield } \\
\text { stage }\end{array}$ \\
\hline \multirow{4}{*}{$\begin{array}{l}\text { Moment } \\
\text { (kN.m) }\end{array}$} & Test & 12.7 & 74.0 \\
\cline { 2 - 4 } & Estimation & $\begin{array}{c}14.8 \\
(7.1)\end{array}$ & $\begin{array}{c}151.6 \\
(75.8)\end{array}$ \\
\cline { 2 - 4 } & Ratio\$ & $\begin{array}{c}1.17 \\
(0.56)\end{array}$ & $\begin{array}{c}2.05 \\
(1.02)\end{array}$ \\
\hline \multirow{4}{*}{$\begin{array}{l}\text { Shear force } \\
(\mathrm{kN})\end{array}$} & Test & 12.7 & 74.0 \\
\cline { 2 - 4 } & Estimation & $\begin{array}{c}14.8 \\
(7.1)\end{array}$ & $\begin{array}{c}151.6 \\
(75.8)\end{array}$ \\
\cline { 2 - 4 } & \multirow{2}{*}{ Ratio\$ } & $\begin{array}{c}1.17 \\
(0.56)\end{array}$ & $\begin{array}{c}2.05 \\
(1.02)\end{array}$ \\
\hline
\end{tabular}

${ }^{\$}$ Estimation / test, (xx): Half section width

section width and beam half section width. The concrete and reinforcement strength considered in the evaluation were those obtained by laboratory tests.

The estimated performance of the global behavior of the beam at the crack stage and yield stage were compared to the test results as presented in Table 4. Generally, measured and estimated forces were close at cracking when full beam section width was considered and at yield when half beam section width was used for the evaluation. This is explained by the reduction in the effective section as presented in the following sections.

During loading, the tested beam experienced a progressive crack pattern (Fig. 12) located mainly between the loading points. At the beginning of loading, the first crack appeared at the transverse joint interface when the loading level reached $\mathrm{Q}_{\mathrm{y}} / 8=9.80 \mathrm{kN}$ (corresponding to deflection $d_{c}=0.76 \mathrm{~mm}$ at mid-span). The first flexure cracks started around the location of the transition section at $\mathrm{Q}_{\mathrm{y}} / 6=13.7 \mathrm{kN}\left(\mathrm{d}_{\mathrm{c}}=1.16 \mathrm{~mm}\right)$. The majority of cracks closed or considerably narrowed after unloading stage $\mathrm{Q}_{\mathrm{y}} / 3$. Basically, flexure cracks were predominant until almost loading level $2 \mathrm{Q}_{\mathrm{y}} / 3=50.5 \mathrm{kN}\left(\mathrm{d}_{\mathrm{c}}=7.67\right.$ $\mathrm{mm}$ ) and concentrated between the loading point section and the lap splice mid-length. After that level, flexure shear cracks had developed due to the interaction between the bolts and the lap element and were mainly concentrated in the lap splice. When tensile yielding of main reinforcement occurred at the transition section when the loading level reached $\mathrm{Q}_{\mathrm{y}}=75.8 \mathrm{kN}\left(\mathrm{d}_{\mathrm{c}}=\right.$ $16.80 \mathrm{~mm}$ ), cracks perpendicular to the transverse joint appeared at the upper part of the lap elements due to the high compression stresses. The increase in shear force became limited and deflection increased consistently. The ultimate level was reached when the concrete of the upper part of the lap elements at the location of the transition section reached crushing at $\mathrm{Q}=84.00 \mathrm{kN}\left(\mathrm{d}_{\mathrm{c}}=\right.$ $38.70 \mathrm{~mm}$ ) simultaneously with yielding of compressed main reinforcement. The strains in the transverse reinforcement along the lap splice connection were very low, accounting for a maximum of $\varepsilon_{\mathrm{y}} / 4$ at maximum loading. Furthermore, although some negligible torsion along the lap elements was noticed through the course of the cracks and recorded data, at the end of testing, damage could be found neither in the bolts nor in their surrounding grout. For illustration, Fig. 12 shows the developed crack pattern within the loading area at different loading levels.

The growth of cracks was recorded at different locations and at different loading stages. The cracks at the joint interface had large widths, while those within the bolt zone and on the lap element were moderate or small. At loading levels $1 / 3 \mathrm{Q}_{\mathrm{y}}$ and $2 / 3 \mathrm{Q}_{\mathrm{y}}$, the crack width at the transverse joint was, respectively, $0.25 \mathrm{~mm}$ and 0.95 $\mathrm{mm}$ while cracks in other locations were negligible or less than $0.06 \mathrm{~mm}$. From loading levels $2 / 3 \mathrm{Q}_{\mathrm{y}}$ to $0.8 \mathrm{Q}_{\mathrm{y}}$ almost all crack widths remained stable except the crack at the transverse joint, which increased with loading. Then from $0.8 \mathrm{Q}_{\mathrm{y}}$, while the width of the transverse joint crack kept increasing, the width of other cracks increased slightly until $0.9 \mathrm{Q}_{\mathrm{y}}$, then again decreased until it reached loading level $1.0 \mathrm{Q}_{\mathrm{y}}$ and then remained stable (maximum recorded $0.06 \mathrm{~mm}$ ) until the end of loading. The crack width at the bottom of the transverse joint (referred to as $A_{b}$ in Fig. 13) reached $9.50 \mathrm{~mm}$ at the ultimate stage. The evolution of the crack width at the transverse joint is illustrated in Fig. 13. Other relative displacements (vertical and transversal) along the joint interface are also shown in the same figure. The measured relative displacements on the symmetric sides of the joint were similar. Compared to the anti-symmetric loading, though some cracks appeared on Beam B-M, the torsion along the lap elements was not intense (refer to displacement $T_{b}$ in Fig. 13) and did not affect the beam, particularly below loading level $2 / 3 \mathrm{Q}_{\mathrm{y}}$. Torsion was also confirmed by the recorded axial strains of the bolts. These strains were very low (the maximum axial strain reached $1 / 3$ of the yield level).

Furthermore, as mentioned at the beginning of this chapter, measured and estimated forces were close at the beginning of cracking when full section width was considered and at yield when half section width was considered. While the first case result was explained by the 

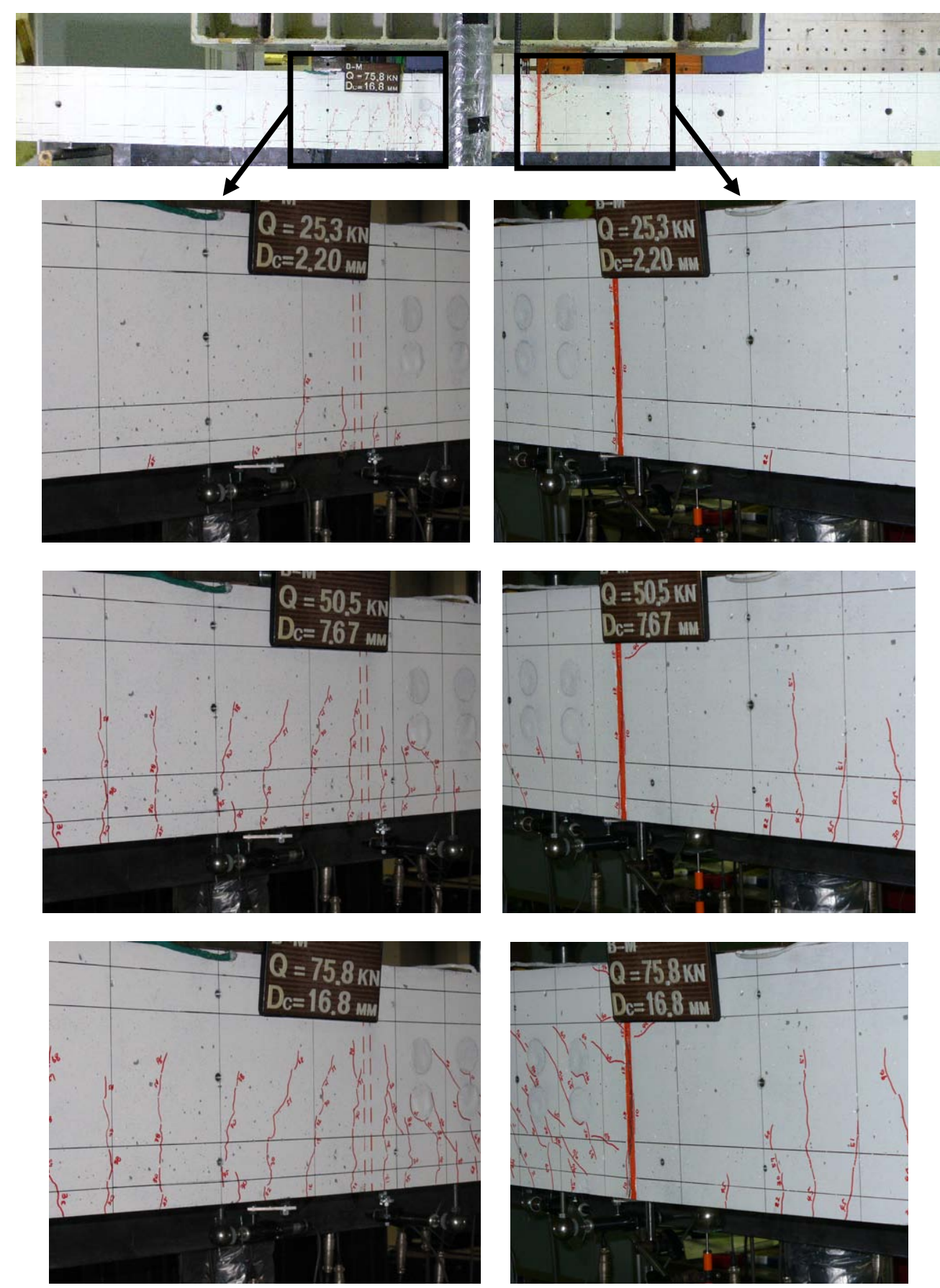

Fig. 12 Crack pattern appearance at different load stages until yield level of beam B-M (the joint location is indicated by the vertical orange line).

absence of cracks and the beam section responded fully to the applied load, the second case result was explained by the spreading of cracks along the loading length and mainly by the evolution of the crack at the joint interface along the lap splice. The crack at the joint interface revealed the influence of the sudden variation of the cross section along the precast cantilevers through the reduction in the effective flexural stiffness of the as- sembled beam along the span.

By considering the equations of beam theory, the evaluation of flexural stiffness EI was carried out through measurement of deflection y and curvature $\phi$ using displacement transducers along the beam under the four-point loading where location $\mathrm{x}$ of the sections in question is shown in Fig. 15. 


$$
\begin{aligned}
& E I=\frac{1}{\phi}\left\{\begin{array}{lr}
Q x & 0 \leq x \leq a \\
Q a & a \leq x \leq L / 2
\end{array}\right. \\
& E I= \\
& \frac{1}{2 y}\left\{\begin{array}{cc}
Q\left\{x^{3} / 3-a(L-a) x\right\} & 0 \leq x \leq a \\
Q a\left\{x^{2}-L x+a^{2} / 3\right\} & a \leq x \leq L / 2
\end{array}\right.
\end{aligned}
$$

The evaluated flexural stiffness at load location $\mathrm{x}=\mathrm{a}$ was taken as a reference in order to present the variation of the flexural stiffness at location $\mathrm{x}=5 \mathrm{~L} / 12$ corresponding to the location of the transition section and at

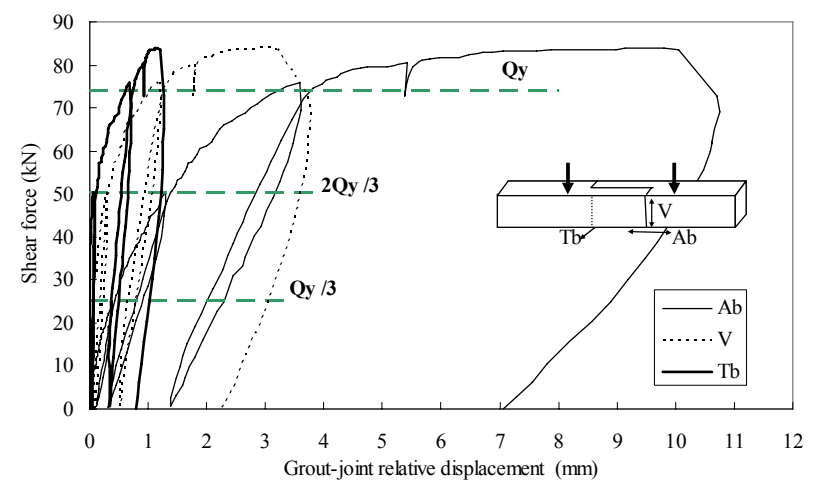

Fig. 13 Relative displacements at grout-joint interface of beam B-M.

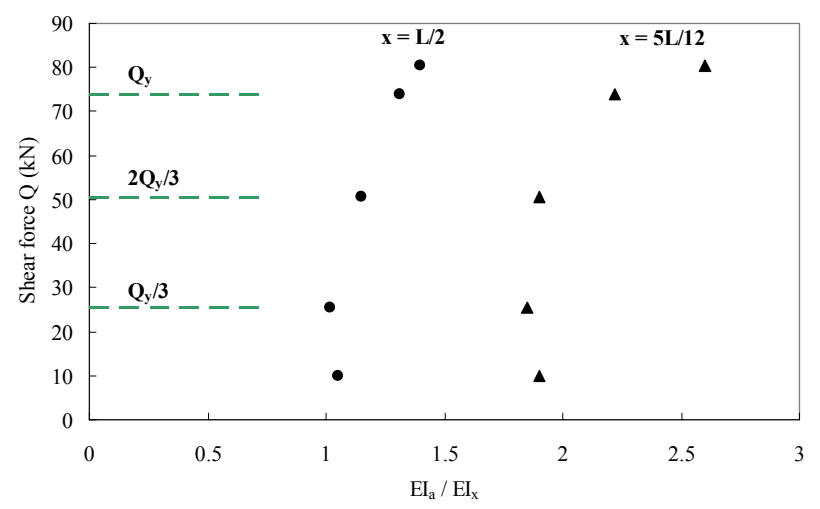

Fig. 14 Variation of flexural stiffness ratio of tested beam B-M. mid-span $\mathrm{x}=\mathrm{L} / 2$. The flexural stiffness ratios (defined by the ratio $\mathrm{EI}_{\mathrm{a}} / \mathrm{EI}_{\mathrm{x}}$ where $\mathrm{a}=\mathrm{L} / 3$ and $\mathrm{x}$ is the location of the sections in question) seemed to revolve around some values when loading did not exceed the yield level as shown in Fig. 14, where $\mathrm{EI}_{\mathrm{x}=\mathrm{L} / 3} / \mathrm{EI}_{\mathrm{x}=\mathrm{L} / 2}=1.10$ (assumed to represent the beam section reduction $\alpha / \gamma$ in Fig. 15), and $\mathrm{EI}_{\mathrm{x}=\mathrm{L} / 3} / \mathrm{EI}_{\mathrm{x}=5 \mathrm{~L} / 12}=2.00$ (assumed to represent the beam section reduction $\alpha / \beta$ in Fig. 15)

As a consequence, the effective section (or effective moment of inertia) of the assembled beam cross-section seemed to contract (or decrease) when the transition section $(\mathrm{x}=5 \mathrm{~L} / 12)$ was reached and then expand (or increase) again slightly at beam mid-length, as shown (schematically and not exactly) in Fig. 15. The effective beam width intervening in this case influenced considerably the effective section.

Therefore, based on a comparison of the results of both tests, the reduction in the effective cross-section and flexural stiffness as measured on the simply supported precast beam would not jeopardize the performance within the design limits of the fixed-end assembled precast beam. The shear force that would be attained under four-point symmetric monotonic loading (distance between loads kept fixed to $1.00 \mathrm{~m}$ ) for a simply supported beam of $2.20 \mathrm{~m}$ length is $66.6 \%$ higher than its similar simply supported beam with $3.00 \mathrm{~m}$ length. Furthermore, the shear force that would be attained under four-point symmetric monotonic loading for a fixedends beam of $2.20 \mathrm{~m}$ length is $266.7 \%$ higher than its similar simply supported beam with $2.20 \mathrm{~m}$ length. By considering these increases and if the design limit is lower than $2 / 3$ of the yield level reached by the simply supported beam B-M, the beam would perform relatively well, though a slight reservation about the crack width (referred to as $A_{b}$ in Fig. 13) at the transverse joint.

\section{Conclusions}

This study presents an innovative connection for assembling high-strength concrete precast beams aimed for high-rise buildings in seismic regions. The connection not only is simple in practice, it reduces the amount of cast-in-place concrete, shortens the time of implementation, and thus results in a lower construction cost. The

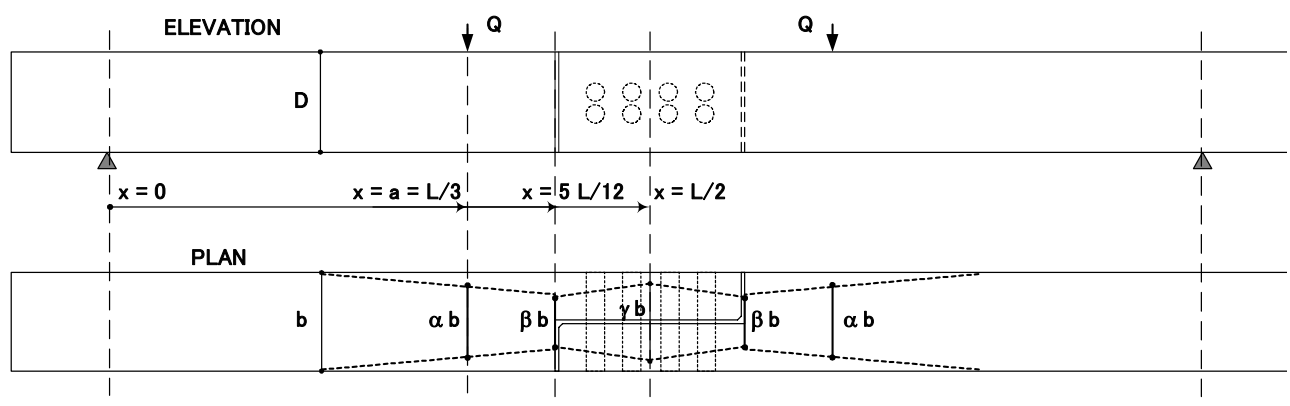

Fig. 15 Actual effective section width beyond cracking along tested beam B-M. 
connection is conceived with non-tensioned tying bolts at beam mid-span away from beam-column joints. The tests carried out on the presented type of the assembled precast beam confirmed the feasibility and adequacy of the selected assembly and connection type.

The assembled precast beam when tested under simulated seismic loading proved to be ductile, did not experience any strength deterioration even at large deflection angles and failure occurred outside the lap splice connection similarly to ordinary monolithic beams. The performance, in terms of strength-deflection angle relationship, energy absorption and damage concentration, was very satisfactory, despite the abrupt variation of cross-sections in the lap elements.

The assembled precast beam when tested under fourpoint loads to evaluate its performance under simulated service loading as well as to investigate the variation of the flexural stiffness along the central zone of the precast beam, showed good characteristics when the results of the simply supported beams were converted to fixedend beam. Furthermore, the reduction in the effective flexural stiffness or the effective section width at the location of the transition section seemed not to jeopardize the performance of the assembled precast beam within design limits.

Therefore, while the results reported in this study are related to a connection of relatively shallow beam types of rectangular section, future investigation of the case of similar beams with higher section height and the effect of the slab is called for.

\section{References}

Abd-Rahman, A. B., Leong, D. C. P., Saim, A. A. and Osman, M. H. (2006). "Hybrid beam-to-column connections for precast concrete frames." Proceeding of the 6th Asia-Pacific Structural Engineering and Construction Conference (APSEC2006), Kuala Lumpur, Malaysia, A281-A290.

AIJ (1985). "Design recommendation for composite constructions." Architectural Institute of Japan, 255 pages. (Japanese)

AIJ (1990). "Ultimate strength and deformation capacity of buildings in seismic design." Architectural Institute of Japan, 713 pages. (Japanese)

Amaris, A., Pampanin, S. and Palermo, A. (2006). "Uni and bi-directional quasi-static tests on alternative hybrid precast beam column joint subassemblies." Proceeding of the 2006 New Zealand Society of Earthquake Engineering Conference, Napier, New Zealand, Paper P24.

BD (2003). "Code of practice for precast concrete construction." Buildings Department, The Government of the Hong Kong Special Administrative region, $73 \mathrm{p}$.

Hieber, D. G., Wacker, J. M., Eberhard, M. O. and Stanton, J. F. (2005). "State-of-the-art report on precast systems for rapid construction of bridges." Technical Report for Washington State Transportation Commission, Department of Civil and Environment Engineering, University of Washington, $112 \mathrm{p}$.

Khaloo, A. R. and Parastesh, H. (2003). "Cyclic loading response of simple moment-resisting precast concrete beam-column connection." ACI Structural Journal, 100(4), 440-445.

Khoo, J., Li, B. and Yip, W. K. (2003). "Tests on precast concrete frames with connections Constructed away from column faces." ACI Structural Journal, 103(1), $18-27$.

Miller, R. A., Castrodale, R., Mirmiran, A. and Hastak, M. (2004). "Connection of simple precast concrete girders for continuity." Report 519, National Cooperative Highway Research Program, Transportation Research Board, 202 p.

Ousalem, H., Ishikawa, Y., Kimura, H. and Okamoto, J. (2008a). "Experimental study on the seismic performance of assembled precast high-strength concrete beams." Proceedings of the Japan Concrete Institute, 30(3), 295-300.

Ousalem, H., Takatsu, H., Ishikawa, Y. and Kimura, H. (2008b). "Seismic performance of precast exterior beam-column joints with high-strength materials under high-axial tension loads." Proceeding of the 8th International Symposium on Utilization of HighStrength and High-Performance Concrete, Oct. 27-29, 2008, Tokyo, Japan, Paper S1-8-4.

PCI (1997). "Parking structures: Recommended practice for design and construction." Precast/Prestressed Concrete Institute, $125 \mathrm{p}$.

Stone, W .C., Cheok, G. S. and Stanton, J. F. (1995). "Performance of hybrid moment-resisting precast beam-column concrete connections subjected to cyclic loading." ACI Structural Journal, 91(2), 229249. 